\title{
Comprendiendo Nuestras Politicas: The Need of an Effective C\&IT Policy for a Nation's Development, The Venezuelan Case
}

\author{
Carmen Joham \\ University of South Australia, Adelaide, Australia
}

Carmen@joham@unisa.edu.au

\begin{abstract}
This research explores the argument that developing countries (DC) need effective and good quality C\&IT policies as a strategy for socio-economic growth. It focuses on Venezuela and attempts to gain an understanding of the current and potential impact of national C\&IT policies and strategies in the C\&IT diffusion process and globalisation arena. It is suggested that a shift is needed towards a wider concept of policy design. The traditional design reflects a rather 'prescriptive' approach, while I propose that a 'participatory' approach, which encompasses social, political, technical, ethical and other issues, is both necessary and desirable for effective policies to exist. A multiple perspective interpretative methodology is used in order to understand the complexities of effective C\&IT policies in Venezuela to attract C\&IT investment and achieve socio-economic growth. Consequently, the study of C\&IT policy is based on an approach that emphasises a multiple level of analysis encompassing the levels of the individual, society, organisation, and technology.
\end{abstract}

Keywords: C\&IT national policy, developing countries, information technology, Venezuela

\section{Background}

This research explores the argument that Venezuela's communications and information technology (C\&IT) policy is not effective enough for a LDC wishing to achieve socio-economic growth. Venezuela is presented here as a case where the basic requirement of policy formulation has not been forthcoming, in particular the traditional policy making-design has resulted in a less than optimal development of electronic communication and information systems (Coronil, 1997). This is partly because their policy formulation processes appear to be from a prescriptive position rather than a participatorier one. The evidence to support this comes from an analysis of the country's current legislation, strategies and multinational C\&IT companies that have raised concerns in investing under this environment.

Madon (1997) argues that Information Technology is at the core of the current process of economic globalisation. Countries are being encouraged to attract economic growth by entering the information age and being able to supply or compete at the multinational level. National C\&IT policies play an important role in enabling this to occur. It is therefore important for developing countries (DC) to focus on strategies that

Material published as part of these proceedings, either on-line or in print, is copyrighted by Informing Science. Permission to make digital or paper copy of part or all of these works for personal or classroom use is granted without fee provided that the copies are not made or distributed for profit or commercial advantage AND that copies 1) bear this notice in full and 2) give the full citation on the first page. It is permissible to abstract these works so long as credit is given. To copy in all other cases or to republish or to post on a server or to redistribute to lists requires specific permission from the publisher at Publister@intormingscience.org enable them to take advantage of the new technologies and so build essential communications and information systems (C\&IS) in order to partake in the global economy. Unfortunately in most developing countries (DC) there exists a gap in these C\&IT systems. This gap is even more severe in rural areas, because traditional sources of information and communication cannot be accessed properly. For exam- 
ple, in Venezuela, remote hospitals cannot access information that could answer medical questions in crucial situations, most university libraries are poorly stocked, and distance learning is a distant dream. To a significant extent, non-government organisations also experience information and communication problems. National C\&IT companies are unable to access their own country's supply chain.

To fill in these gaps it may be important for DC to give more priority to the enactment of effective C\&IT policies as a main strategy for the diffusion and adoption of new technologies. Furthermore, Sachs (2000) reflects the importance of this issue by highlighting that countries lacking these strategies often collapse and are unable to achieve socio-economic growth. Lal (2001) as well as others observes this and in addition argues that the lack of existing information infrastructure in remote communities is considered to be one of the major impediments in the diffusion of C\&IT. Information infrastructure includes the development of technological capabilities for use and production of C\&IT. These capabilities can be divided into three categories: global information, national information infrastructure and local information infrastructure. Governments can play an important role in building a proper information structure if effective strategies and policies are in place and if stakeholders fully participate in policymaking processes. Effective policies are of increasing importance if countries want to benefit from the global stock of knowledge.

\section{The State of C\&IT in Socio-Economic Development}

Adapting from Todaro's (1994) definition, the objective of development in this research implies the acceleration of socio-economic growth, the suppression of poverty and the reduction of inequality. A number of significant successes in transforming of rural communities are linked to C\&IT (Castells, 1996).

DCs when building up their strategies should consider which of the benefits found in these successes are feasible for their own environment. Some of the benefits, as highlighted in the C\&IT literature for developing countries are summarised as poverty alleviation, education, health, and economic productivity (see, for example, the proceedings of the IFIP WG 9.4 conferences: 1993-1996). However, for some countries C\&IT may not necessary be perceived as 'beneficial'. Conversely, there is no doubt that it could be used to accelerate the development process in a nation.

Communication, for example, is a convincing evidence of progress in the world... Telephones, TV, Internet, etc brings immediate contact with people and events from around the world ... and engender the knowledge required for development.

There is no hesitation of the importance that governments attach to deploying strategic communication and information systems. However, serious constrains, mainly in human resources and institutional capacity, may slow down their progress (Gomez, 1998), but DCs almost without exception have realised that deployment of effective and strategic C\&IT systems are a necessity rather than a choice for national socio-economic development. Consequently, many countries have committed to advanced Communication and Information Technology for the improvement of their societies. Distinctly diverging densities of uptake and incursion have emerged, generally determined by the affluence, capacities, value systems, and the competitive market dynamics of individual economies. These inequities in comparative adoption rates seem, however, to beg particular concern for DCs with low rates of C\&IT ingression. These countries may be seen to be missing out on the potential of C\&IT to assist their participation in the seeming benefits of the 'information age'.

\section{The Global Arena}

Having recognised the state of C\&IT in the processes of social and economic changes in DCs, Walsham (2000) and others point out that 'the process of globalisation is also affecting the poorer countries of the world'. The global environment also influences the policies of national governments and defines the opportunities and challenges facing policy makers and business leaders. Kraemer and Dedrick (2001) assert 
that the C\&IT industry is highly globalised. Therefore, developing countries, and in particular, remote communities as a whole, would have to participate extensively in the acceleration of global integration by assisting in defining national C\&IT policies if they wish to become part of the 'information rich'.

The significance of communication and information technologies is a recurrent theme in the globalisation literature. These technologies have an enabling role for the globalisation trends. Avgerou (1998) highlights that they form the means for compression and transgression of time and space barriers. 'Globalisation' meaning the many ways in which space and time have been compressed by technology, information flows, trade and power so that distant actions have local effects. Madon (1998) argues that C\&IT are major determinants of competitiveness in global industries. This is related to the increasing importance attributed to using communication, information and knowledge as a factor of production and competitiveness. Globalisation is inevitable, and is not just a late $20^{\text {th }}, 21^{\text {st }}$ century phenomenon. The Romans, Dutch, Spanish, English were all globalisers at different times in history.

Cerny (1999) asserts that globalisation gives states strong incentives to rearticulate themselves. For the hallmark of globalisation is the technologisation of trade, that is, the increasing salience of high technology products in global trade. This creates incentives for states to employ strategic trade and investment policies for developing domestic "architectures of supplies" in significant technologies (see, for example, the case of Singapore and India: Wong, 1998; Madon, 1998). Wong (1998, p336) argues that developing countries 'can indeed leverage the rapidly expanding global information economy as engine for socioeconomic growth'. Moreover, he highlights the importance in having a process of effective policy coordination as a major contributing factor to the success of a country's C\&IT growth in the global arena. Developing countries must build up effective policies to assure their potential to participate more actively in world trade but must preserve with their growing efforts to improve local conditions for entrepreneurship and expand domestic C\&IT capacities to produce and export.

\section{Policy Definition}

It has been argued (see for example, Manor 1991, Bridgman and Davis 2000) that there is a difference between policy, legislation and regulation. Legislation is considered to be the process of deliberate law making or law-changing by an expression of the will of a recognised governmental body that has the power and authority validly to declare law. Regulation subordinates legislation by prescribing acts and rules in the legal system intended by the government. Whereas 'policy' (Greek politeia, government) is the general considerations which the government has in mind in legislating, deciding on a course of action or otherwise acting. Consindine (1994) argues that regulation, policy and legislation in combination or alone is what 'governments say and do, or do not do'. Therefore, for the purpose of this study the author will use the term of 'C\&IT policy', based on Consindine's argument, to enclose all actions employed by DC governmental authorities to commit in support of C\&IT activities.

To keep policies focused on objectives and to highlight their effectiveness, policy makers would need to rely on strategies that include project planning and evaluation. In this research, the term strategy embraces the long term planning at the national level to improve the existing use and diffusion of C\&IT for the country's socio-economic development. Furthermore, strategy is seen as a coordinated set of C\&IT policies, which will focus on transforming education, widening access, promoting competition and competitiveness, fostering quality and modernising government.

\section{A Venezuelan Example}

Venezuela is the sixth largest country in Latin America. A country with golden beaches by the Caribbean sea, snow-capped peaks of the Andes in the west, Amazonian jungles in the south, enjoys huge oil revenues and yet has two critical and unresolved long-term issues: a high domestic debt, and an undervalued 
currency. Zaidman (1991) argued that as part of this, Venezuela suffered a 30-year delay in the implementation of C\&IT causing, and reflected in (among other things), the inefficiency of the State in providing stable information and communication technology regulations.

Prior to 1991 Venezuela was far behind much of the world with regard to telecommunications usage. Their infrastructure was unreliable and old, and since the government ran telecommunications, no incentive existed to change. After 1991, things changed very quickly. The government opened all aspects of telecommunications, except basic telephone services. This was the first stimulus for IT growth. Telecommunications became the fastest growing industry in all of Venezuela after the liberalization of 1991. However, as the current stimulus for C\&IT growth in Venezuela is the oil and petrochemical industry growth most of its policies are set addressing these requirements. Other policies addressing IT and science development are often design following the traditional 'prescriptive' view. This traditional view is one that deliberately rules and instructs specific requirements to achieve an outcome, and doesn't accommodate variations.

A one-year pilot research has been conducted in Venezuela obtaining a variety of views and perspectives on the country's C\&IT strategy. Extensive details have been collated as a starting point to proceed with a multiple perspective stakeholders' analysis, yet lack of space prohibits the full reference of this material here. The establishment of an electronic forum collating public opinion by the Ministry of Science and Technology was also used to gain an understanding of the current C\&IT issues -some are highlighted later in this paper-. Unfortunately, a common finding in the data, pointed out that recent changes in the country's legislation and constitution have had a negative impact on foreign investment and local companies. As Hoag (1999) argues, current deregulation of economic policies are scaring away both local and foreign investment. Under these market conditions, the investment in C\&IT has slowed down and directly affected the diffusion of new technology into remote communities.

\section{Determining 'effectiveness' in policy formulation}

Each country of course determines how C\&IT policies are considered to be effective. There is, however, a core group of strategies that characterises the effectiveness of C\&IT policies for a country's continued socio-economic development. Included in this group are strategies that:

$\checkmark$ Support stakeholders' participation in policymaking processes.

$\checkmark$ Increase trade and global competitiveness (if the goods and services of DC are not globally competitive, their national and international markets will vanish under attack from better suppliers in other parts of the world.)

$\checkmark$ Assure stability on regulations (stability defined as 'consistency' of regulations to remain qualitatively unchanged in response to fluctuations of governance)

$\checkmark \quad$ Improve and support delivery of infrastructure services

$\checkmark$ Promotes economic activity and improves infrastructure

$\checkmark$ Develops human resources for the information age

Steps and priorities in each strategy vary in nature, order, and scope in different countries. However, as Wong (1998) highlights, the importance of these strategies are reflected on the level of impact in the country's C\&IT adoption, development and diffusion. For example, Granell (2000) referred to a recent study, which collected data from seven regions to highlight that stability - out of other ten issues raised was the number one issue for Venezuelan and Asia-Pacific companies. This also emerged out of twelve informal interviews I conducted by email. The interviewees were all senior managers within IT Departments from private and public Venezuelan corporations. All respondents were concerned about what they felt was a need to improve Venezuelan traditional practices, as globalisation forces them to adapt to a 
competitive environment. The constant change of governance was believed to be very detrimental to the processes of attracting investment. This seems to have affected the next most pressing issue, that of being able to take advantage of technological advances and skill shortages.

Unfortunately, Venezuela's current legislation is not enabling the country to move forwards in the information economy. Halachmi (1997) points out that political-cultures in developing countries, such as Venezuela, are a turn off for foreign investments. If investors partly drive socio-economic development, how can a market be attractive if there is government instability and several changes of regulation? Furthermore, how can small businesses, in a remote environment particularly, participate in the information age? Shahidullah (1998) asserted that there is no guarantee of development where policy-making is entirely based on politics. 'Ideology, common sense and culture need to play a role in policy-making' .

The concept of a national information policy in Venezuela first began to emerge in the early 1990s as the responsibility of the state in dealing with poverty and equity, and to further develop the nations' information systems. Halachmi (1997) also outlines that in some countries the concept of a national information policy emerged due to an absence of these types of policy. This may well be the case in Venezuela. The Venezuelan government created a 'Council for C\&IT' to alleviate poverty and progress IT development. However, to date the country's C\&IT policy falls under the Ministry of Science and Technology (MCT) (Olavarria, 2000) and its supportive legislation. This means that the focus is on research and product development not national hard and soft infrastructure.

\section{Participatory Process}

Thajchayapong et al (1997) argue that governments in developing countries usually declare policies that are incompatible with the country's national information infrastructure, the innovative nature of technology and the global market culture. Effective policies should optimise benefits from innovation and not serve as a restrictive tool for corporate investment. Castells $(1996,1997,1998)$ points out that in most Latin American countries C\&IT legislation is obsolete and constricting. Accordingly to Salas et al (1999) C\&IT policies in DCs are limited by not accepting the decentralised nature of C\&IT development, and so should avoid prescriptive legislation. One of the main problems in the Venezuelan case is that the government does not encourage citizen participation, and civil society does not influence government decisions.

Given the rapid change in technology, effective policy means one that is able to accommodate changes. This requires that it not be prescriptive but rather provide a regulatory infrastructure for technology to develop. Typically, this means that the policy needs to be objective in stating what outcomes are sought, and what behaviour will not be tolerated. Some Venezuelan's have identified this issue in the country's current C\&IT policies. This is reflected by the following comments obtained from an open forum established by MCT to collate public opinion concerning these policies (a translation from Spanish to English has been conducted).

"...if a fixed policy is going to exist there must be a stable framework to facilitate the rules of the game, not to command nor to scare possible investors...”

“...you cannot decree technology; ask China and what is left of Russia...”

“..an error in upper case...”

“... a modern and global world is not compatible with this type of regulation...”; “...it is very vague and it is not clear which stakeholders are involved in this national information systems plan..."

Flexible procedural legislation is better achieved with open participation between the stakeholders involved. Policy formulation appropriate to aligning the needs of globalisation should be developed through a process of consensus. Hellstrom (2000) highlights that the goal of consensus approach is to combine the 
best available knowledge with social positions taken by interested groups. Consequently policy support is likely to evolve when it can be shown that consensus processes allow better quality policies. Government, industry and the broader community need to work together to become committed to a policy that will then be able to stand for some time and support regional development. As Gurstein (2000) highlights, regional development - 'between community access, regional coordination, regional public administrations and existing areas of local specialisations' - depend on effective C\&IT policy, one that catalyses and elaborates on consensus and community success. A policy set up in isolation will be changed as soon as the opposition gets the opportunity. This can be a difficult process without a fully democratic style of governance.

Another example pointing Venezuela's prescriptive view in the process of policy formulation is Article 35 and 36- Section 5 of the 'Ley Organica de Ciencia, Technologia e Innovacion' (English literal translation: Organic Law of Science, Technology and Innovation). The policy here refers to a predefined or predetermined process set by policymakers in which technology innovation and investigation objectives restricts the academic freedom, spontaneous participation and autonomy in the formation of international academic alliances. One of the stakeholders interviewed responded to this issue by highlighting that 'the problem when you are trying to incorporate a unique plan designed in isolation is that you are discarding all the advantages that the own science \& technology offers: one of which is innovation itself'. The suggestion of a mix of political wills, technical capacity and partnership with civil society to enhance efficiency, equity, and transparency in C\&IT policy formulation is relevant to this matter.

I would also argue that policies should not depend on funding, but priorities within those policies should. These need to be set given the funding available. If there is to be no funding from Government then a different priorities within these policies will need to be set up compared to a fully funded ones. Moreover, it will need to be set up to attract funding. Unfortunately, as Thajchayapong et al (1997) highlighted, policymakers often write their legislation before considering the availability of the nation's budget. Funding should drive the nature of the countries' C\&IT legislation else it would be almost impossible to build an effective national information system.

MCT's forum provides an important insight into the country's perceptions towards globalisation and its relation to current C\&IT policies. Most of the debate illustrates how the legislation lacks monetary resources. Venezuela is not dedicating the resources that some believe are needed to turn the present policy into reality. Gurstein (1999) argues that technology policy is a good investment as it also enables the mobilisation of a much wider and more sophisticated range of resources to support local economic development initiatives than has ever been possible. On the whole, Venezuela is left facing few challenges: political instability \& corruption, lack of monetary funds, C\&IT market competition \& global threats, and the absence of C\&IT policies that can assist in the diffusion and adoption of new technologies.

\section{Methodology}

Formulation of a national C\&IT policy should ideally be demand-driven and achieved through a broad based participatory process because these policies cannot be deployed effectively without the active cooperation of all stakeholders. The purpose of a multiple perspective strategy is to address the needs and concerns of all identified stakeholders groups, adding a further human dimension through the process of problem-solving by developing and including communication strategies. A proposed analytical framework that includes the interactions among the elements of a country's policy network and stakeholder groups; that is, among government policies, information infrastructure, the C\&IT industry and the markets is illustrated in Figure 1 (please note that according to Mitroff and Linstone (1993) stakeholder identification are 'any individual, group, organization, institution that can affect as well as be affected by an individual's, group's, organisation's, or institution's policy or policies). A further approach intended for this research is to emphasise on a multiple level of analysis encompassing the levels of technology (T), 
organisation (O), and individual-society (P) perspectives, as suggested by Linstone (1983). Further qualitative semi-structure interviews are intended combined with a content analysis of media articles that raises C\&IT policy issues within Venezuela.

International trade and investment are driving globalisation, which in turn are spurred on by the borderless world produced by swift advances in C\&IT. New forms of governance are necessary to referee the changing rules of the game and ensure the effective implementation of public policy in accordance to regional development. As technology changes rapidly, policies should be able to adjust and remain outcome focused. With the incorporation of T, O, P perspectives, I attempt to highlight that the need of a wide participation of stakeholders, is clearly a best practice when formulating policies for DC aiming to achieve socio-economic development. A series of analytical studies are required to gain understanding of current resources, problems, opportunities, and needs in order to reach consensus on a policy strategy, and gain commitment for its implementation. The stories and insights provided by Venezuelan stakeholders would bring to light the country's actual needs.

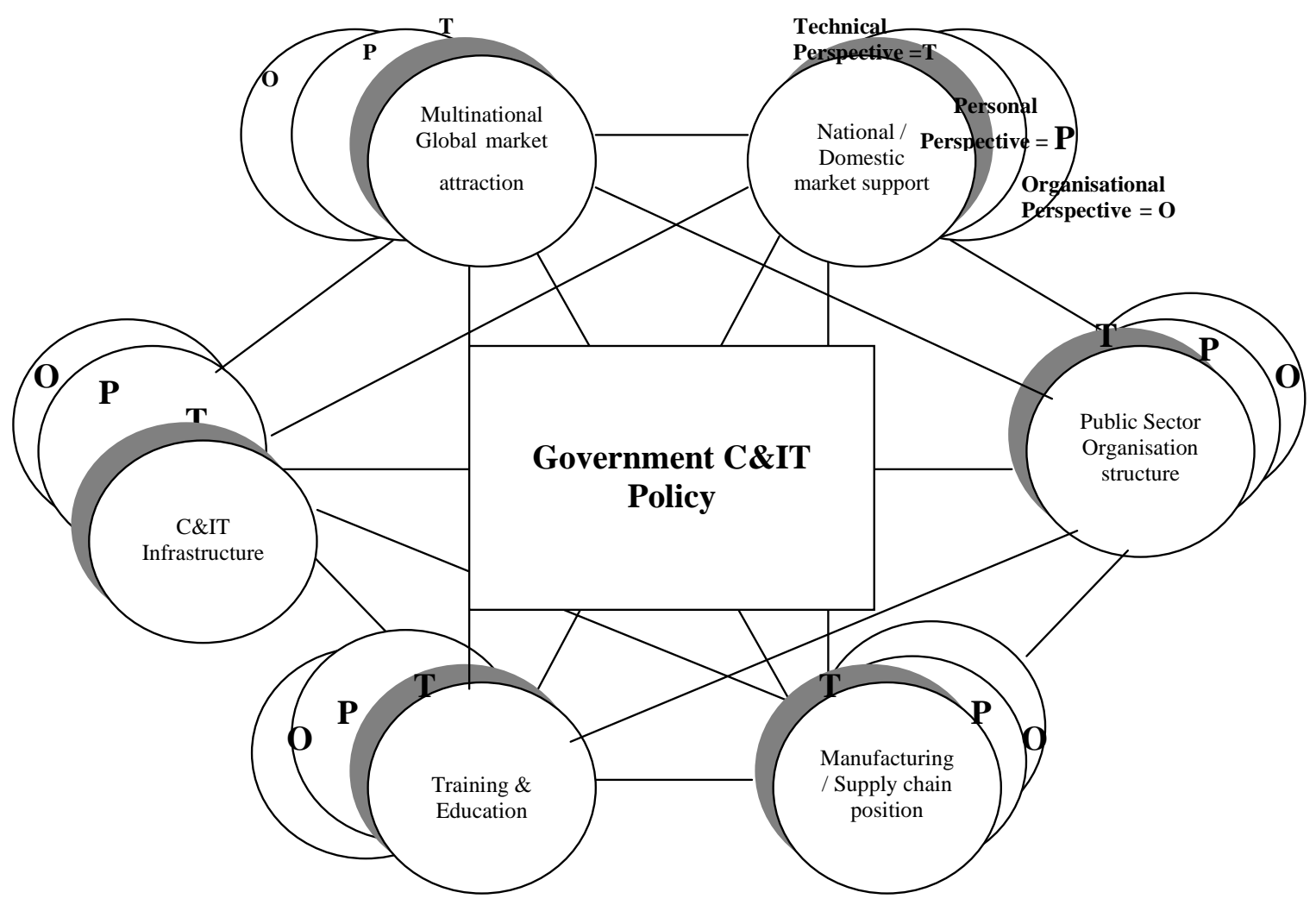

Figure 1. Viewing policy networks and stakeholders groups

\section{What next?}

Future research is required in order to find ways to protect and promote stable public policy goals in the competitive market of global economy. Kirlidog (1996), Gomez (1998) and Montealegre (1998) suggest that some developing countries have adopted a strong foundation on C\&IT policies and attracted global corporations. However, others have a long way to go before becoming an effective 'global' marketplace. It is precisely at such moments that clear and stable policies are required to bring to the fore the competi- 
tive advantages of the country's market environment, particularly those isolated from the 'information age'.

For good or for bad, the evolution of the global economy is seen as having an impact in today's communities. These communities are becoming ever more subject to external forces over which they have little or no control. The traditional policy design view - does not appear to assist in this matter. I propose, rather a participatory policy, a more democratic process that encompasses, social, political, technical, ethical and other issues. This is both necessary and desirable. However, flexible networks should be established between experts, policymakers and government bodies in order to open negotiations and allow for consensus to emerge. Ways to incorporate these bodies into the decision-making processes of policymaking are also required, and a multiple perspective strategy may provide the necessary tools to begin this analysis. The researcher will explore how this maybe achieved. The way to avoid political systems' instability is beyond the scope of this paper.

\section{References:}

Avgerou, C. (1998). How Can IT Enable Economic Growth in Developing Countries? Information Technology for Development, 8(1), 15.

Bridgman, P. \& Davis, G. (2000). The Australian Policy Handbook ( $2^{\text {nd }}$ ed.). Australia: Allen \& Unwin.

Castells, M. (1996). The Rise of the Network Society. Oxford: Blackwell.

Castells, M. (1997). The Power of Identity. Oxford: Blackwell.

Castells, M. (1998). End of Millennium. Oxford: Blackwell.

Cerny, P. (1999). Globalization, Governance and Complexity (pp. 189-212). London and New York: Routledge Taylor \& Francis Group.

Considine, M. (1994). Public Policy: A critical Approach. Australia: Macmillan.

Coronil, F. (1997). The Magical State: Nature, Money and Modernity in Venezuela. University of Chicago Press.

Gomez, R. (1998). The Nostalgia of Virtual Community: A Study of Computer-mediated Communications use in Colombian Non-governmental Organisations, Information Technology \& People, 11(3), 217-234.

Granell, E. (2000). Culture and Globalisation: A Latin American Challenge. Industrial and Commercial Training, 32(3), 89-93.

Gurstein, M. (2000). Flexible Networking, Information and Communication Technology and Local Economic Development. First Monday, 4(2).

Halachmi, A. (1997). Government Reforms and Public Productivity: Do we have all the answers?. Work Study, 46(7), 233245.

Hellstrom, T. (2000). Technoscientific Expertise and the Significance of Policy Cultures. Technology in Society, 22, 499-512.

Hoag, C. (1999, September). Put Money into Venezuela? No, Thanks: Chavez' Political Moves are Scaring off Investors. Business Week, 54.

Kirlidog, M. (1996) Information Technology Transfer to a Developing Country. Information Technology \& People, 9(3), 5584.

Kraemer, L. \& Dedrick, J. (2001) Liberalization and the Computer Industry: A Comparison of Four Developing Countries. The Information Society, 17, 83-90

Lal, K. (2001) Institutional Environment and Development of Information and Communication Technology in India. The Information Society, 17, 105-117.

Linstone, H. (1983). Multiple Perspectives for Decision Making. New York: North-Holland.

Madon, S. (1997). Information-Based Global Economy and Socioeconomic Development: The Case of Bangalore. The Information Society, 13, 227-243.

Madon, S. (1998). The Internet and Socio-economic Development: Exploring the Interaction. London School of Economics. 
Manor, J. (1991). Rethinking Third World Politics. New York: Longman.

Mitroff, I. \& Linstone, H. (1993). The Unbounded Mind. New York: Oxford University Press.

MCT - Ministerio de Ciencia y Technologia. Retrieved January 10, 2001 from the World Wide Web http:/Www.conicit.gov.ve

Montealegre, R. (1998). Waves of Change in Adopting The Internet: Lessons from Four Latin American Countries. University of Colorado, College of Business and Administration, Boulder, Colorado USA.

Olavarria, J. (2000, March). Articulos Publicados. El National.

Sachs (2000, June). A New Map of the World. The Economist.

Salas,C., Susunaga, G. \& Agular, I. (1999). The Role Of Innovation in Regional Economic Development, Some Lessons and Experiences for Policymaking. Paper presented to the Third International Conference on Technology, Policy and Innovation: Global Knowledge Partnerships - Creating Value for the $21^{\text {st }}$ Century, The University of Texas at Austin, LBJ School, 30 August - 2 September.

Shahidullah, S. M. (1998). Useful Sociology: Can Sociological Knowledge be Valuable in Policy-Making? International Journal of Sociology and Social Policy, 18(1).

Thajchayapong, P., Reinermann, H., Goodman, S. \& Pipe, G.R. (1997). Social Equity and Prosperity: Thailand Information Technology Policy into the $21^{\text {st }}$ Century. The Information Society, 13, 265-286.

Todaro, M. (1994). Economic Development ( $5^{\text {th }}$ ed.). New York: Longman Publishing.

Walsham, G. (2000). IT Globalisation and Cultural Diversity, Information Technology in Context. England: Ashgate Publishing Ltd.

Wong, P. (1998, December).Leveraging the Global Information Revolution for Economic Development: Singapore's Evolving Information Industry Strategy. Information Systems Research, 9(4).

Zaidman, N. (1991). Telecommunications in Venezuela, Virtual Reality of Information. Retrieved January 21, 2000 from the World Wide Web http://www.V11.org/papers/vene.htm.

\section{Biography}

CARMEN JOHAM has held a number of management positions where she has designed, programmed and supervised the implementation of information systems for business like General Electric, Mobil and IT Universities. She is also a PhD candidate and Research Associate at the University of South Australia's Information Systems Doctoral School. She holds a BA and BSc in Computer Science from the University of CUMT-Venezuela and a Masters in Business Administration from the Adelaide University. Her present research interests include information policy systems and strategies, social aspects of information for socio-economic development and IT diffusion models in developing countries. 